\title{
Considerable Issues for Sustainable Public-Private Partnership (PPP) Project
}

\author{
Md. Abu Rashed \\ Sr. Consultant, Project Development \\ Infrastructure Investment Facilitation Center (IIFC) \\ An enterprise of Economic Relations Division (ERD), \\ Ministry of Finance, Government of Bangladesh \\ E-mail: arashed@infra-bd.com \\ Md. Mahmudul Alam* \\ Postgraduate Student \\ Institute for Environment and Development (LESTARI) \\ National University of Malaysia (UKM), Malaysia. \\ Email: rony000@gmail.com \\ Mohd Ekhwan bin Toriman \\ Associate Professor \\ School of Social, Development \& Environmental Studies (FSSK) \\ National University of Malaysia (UKM), Malaysia \\ Email: ikhwan@ukm.my
}

\section{Citation Reference:}

Rashed, M.A. and Alam, M.M. and Mohd Ekhwan, T. 2011. Considerable Issues for Sustainable Public-Private Partnership (PPP) Project, Res Manageria, Vol. 2(4), pp. 57-65, Available at http://www.assobp.org/Manageria/?wicket:interface=:1:issuelist:8:fulltext::ILinkListen er:: $>$.

This is a pre-publication copy.

The published article is copyrighted by the publisher of the journal.

\footnotetext{
* Corresponding Author

**The views expressed in the research paper are authors' own and do not reflect those of the organizations in which they work.
} 


\title{
Considerable Issues for Sustainable Public-Private Partnership (PPP) Project
}

\begin{abstract}
The implications of Public Private Partnership (PPP) concept has acknowledged utmost attention from different governments around the world especially in terms of service quality, efficiencies in procurement and risk management, extent of investment undertaken by private sponsor and the ability to generate managerial and technical capabilities. PPPs are seen as a way forward for creating a sustainable atmosphere in terms of economic, social and environmental considerations. However, the variations of PPP schemes have their own set of advantage and limitations over one to another vis-a-vis typical public sector procurement. While adopting and promoting PPPs in a country by the government and involving private sector for a particular PPP deal, specific issues and factors associated with the project must be considered for ensuring sustainibility of the project as well as the interst of all stakeholders, i.e, government, private sector and the users. This study focuses on these factors that will help the involved parties to ensure the sustainability of the PPP projects and a fruitful winwin contract.
\end{abstract}

Key Word: Public Private Partnership (PPP); Service Contracts; Management Contracts; Lease Contracts; Concession Contract; Joint Venture; Sustainable Economic Development

\section{Introduction}

PPP describes a government service or private business venture which is funded and operated through a partnership of government and one or more private sector companies. According to Canadian Council for Public-Private Partnership (CCPPP, 2011) PPP is "a cooperative venture between public and private sectors, built on the expertise of each partner, that best meets clearly define public needs through the appropriate allocation of resources, risk and rewards." Governments traditionally use the standard models of public procurement strategy to deliver public services. This involves the use of public, rather than private sector resources. Development of Public Private Partnership (PPP) is an alternative method of implementing public sector infrastructure projects as part of government's role of promoting sustainable economic development where government allows the participation of private sector in developing and implementing an infrastructure business through carefully integrating environmental, economic, and social needs to achieve both an increased standard of living in the short term, and net gain among future generations. However, PPP also promotes sustainable economic development in the non-infrastructure sectors as well like health, education, agriculture, forestry and fisheries through innovative partnership schemes which is economically viable, environmentally non-degrading, technically appropriate, and socially acceptable.

The PPP method rose to prominence in different counties in the early 80 's as governments accumulated large public debts spurred by the recessions of the 70's and the 80's. Governments sought to encourage private investment in national infrastructure in order to reduce public debt and to increase efficiency while minimizing costs. Over the past three decades, governments in both developed and developing countries have embraced PPP as an alternative to the standard models of public procurement strategy to deliver public services. This is especially true for governments lacking in public sector resources to deliver important public services such as healthcare, transportation, energy and etc. PPPs were introduced in 
Britain in the mid 1990s to overcome a shortage in infrastructure investment. This was the beginning of a significant policy based procurement reform in developed countries (Regan, 2009). Since then, PPPs have been widely adapted by both developed and developing countries. PPP broadly aims to ensure sustainable economic development of the economy through:

- Balancing economic, environment and social needs

- Reliving poverty through employment generation

- Meeting the basic needs of humans that requires both economic growth and social equity

- Minimizing environment impacts for development projects

- Optimizing use of available resources including natural resources

There are three main reasons for adopting the PPP approach (Walker). Firstly, the private sector possesses better mobility than the public sector and therefore the private sector is not only able to save the costs of project in planning, design, construction and operation, but also avoid the bureaucracy and to relieve the administrative burden. Secondly, there is a wide spread belief that the private sector can provide better service to the public sector and establish a good public private partnership so that balance risk-return structure can be maintained. And lastly, governments' inability to raise massive funds for large-scale infrastructure projects can be mitigated by private participation (Cheung, Chan, \& Kajewski, 2009). PPP also seeks to capitalize on the comparative advantage of the public and the private sectors in order to optimize the delivery of public services (Rosenaue, 1999). Apart from generating employment and hence acting as catalyst for minimizing the poverty level, in recent days PPP schemes have been used by many governments in promoting non-traditional development projects like environment, housing and even forestry or preserving natural resources considering the fact that the private sector possesses better mobility than does the public sector.

However, there are significant variations in different PPP models with their own limitations and best practices. As risk and responsibilities of the project are distributed amongst the partners there are several factors that need to consider carefully. This study focuses on these factors that will help the involved parties to ensure the sustainability of the PPP projects and a fruitful win-win contract.

\section{Strength and Weakness of PPP Project}

Both public sector and PPP projects are monitored and evaluated by the government and in both cases, the project usually originates from the government (though there are mechanisms to allow unsolicited proposals from the private sector for PPP projects). The government plays a significant role in either scenario. However, there are noteworthy differences. The bureaucratic process in the government with regards to public sector projects typically is long and complicated. With PPP project, this process becomes streamlined. Nevertheless, this apparent lack of bureaucracy can be misleading, since it is being transferred to the private sector where it is not readily visible. Coinciding with this apparent lack of bureaucracy is the shift in the role of the government to more of a monitoring and regulatory function. This change in role is a consequence of the private sector's involvement and a response to the complexities that arise because of it. In spite of its focus for economic and social sustainability through poverty alleviation, the PPP method is not always superior to the public sector project. The advantages and disadvantages of PPP projects are specific to the particular 
project and the context in which it operates. However, the PPP model generally possesses certain strengths and weaknesses over public sector projects.

A PPP project can benefit from lower costs and a shorter construction period (Department of Transport and Regional Services, 2005; Cheung, Chan, \& Kajewski, 2009). A transparent bidding process for a PPP project typically attracts large firms which are more able and efficient. The involvement of the private sector could also be a means of introducing and transferring new technology which is especially important in developing countries (Blaiklock, 2003). Moreover a partnership can draw on the strengths of cooperation and synergy. Most importantly, the public sector can draw on the resources of the private sector to finance infrastructure projects. This is especially important in developing countries, where public sector budget constraints are an obstacle to growth and development. The partnership would also allow some risk to be transferred to the private sector and hence to the party best able to manage them. This will result in gains in performance and productivity (Zou, Wang, \& Fang, 2008). In practice, achieving this is difficult, but if managed properly, the outcome can be more effective risk management. Additionally, contracts can be streamlined and procurement processes simplified in PPP projects, to achieve better results. In addition to this, the inefficient bureaucratic process can largely be avoided, together with politics in procurement.

At the same time, PPP models possess weaknesses of their own. PPP projects are often long term (i.e. 30 years) and involve multiple parties. Because of this, they are much more complicated than normal public sector projects. However, the allocation of risks and responsibilities between the government and private sector generally follows the fundamental that risks are to be borne by parties best able to manage it (Rashed \& Alam, 2009). These complications result in longer negotiation periods and higher costs prior to implementation (Zou, Wang, \& Fang, 2008). These are legitimate barriers to the implementation of PPP projects. Other complications arise due to the difference of interest of the different parties involved. The private sector is more interested in generating a profit while the public sector is interested in serving the public interest. Opportunistic behavior by different parties can lead to higher costs and even failure. Major infrastructure projects involve extensive asset specificity and sunk costs which can provide either public sector or private sector participants with opportunities for hold-up (Globerman \& Vining, 1996; Williamson, 1975; Vining \& Boardman, 2008). The private sector is less concerned in equity and transparency than is the public sector. Issues can arise with regards to access to services by vulnerable populations (Rosenaue, 1999). Moreover, an imbalance in the skills and expertise of the different parties involved can lead to the undermining of one party's interest and result in the failure to achieve equitable outcomes (Miraftab, 2004). Moreover, having its major concern on project cash flow by the project sponsor, PPP also gives less emphasis on issues like climate change, environmental safeguards as part of sustainability concern.

\section{Advantage and Limitations of Various PPP Models}

PPP models exist in a continuum of increasing private sector involvement. This continuum begins with service contracts and continues to concessions. There is significant involvement by the private sector in joint ventures as well. Each of these models has its own advantages and drawbacks. Consequently, some of these models are more appropriate for certain situations than for others. To varying degrees, all of these models have been implemented in Asia (ADB, 2008). The models are discussed below. 
Service Contracts: In a service contract, the government hires a private firm to provide a service and this is usually for a short period of time (1-3 years). The firm is usually selected through a competitive bidding process. Under this model, the government remains the main provider of the service and the private partner only plays a minor role. The private partner generally does not directly interact with the customer. In a service contract, the private sector is typically responsible for its cost but not the project revenue. But, the government bears all the commercial risks and finances any improvements to the system as required. The contracts specify an agreed cost of the service and must satisfy agreed upon performance standards. Service contracts are appropriate in situations where the service is clearly defined, demand is predictable, and performance can easily be monitored. Service contracts can have a significant effect on productivity and can be a means of transferring technology from the private sector. These contracts are short term and have low barriers to entry (since only a discrete service is required and therefore not difficult for private firms to participate). There is also repeated competition since the contracts are short run. Together, these features of the contract pressure the contractor to keep costs down.

On the other hand, service contracts are not appropriate when capital investments are required from the private sector. Since the contract only specifies a discrete service, improvements to the broader system is limited. Also, the government maintains ownership of the asset and sets the tariff. Both of these activities can be politically vulnerable. The service contract is generally used for maintenance, emergency repairs, public information and in education sector.

Management Contracts: Compared to a service contract, management contracts extend the role of the private partner to providing some or all of the public service. In addition to this, the private sector interacts directly with the customer but still does not finance capital investments. In these types of arrangements, a tariff is set by the government and charged to the consumer of the specified service. The government determines how much the contractor is to be paid for labor and other operating costs. Incentives can be incorporated into the contract through profit sharing or incentive payments. However, precautions must be taken to ensure that the contractor does not reduce maintenance or exaggerate achievements to increase profits.

The main advantage to management contracts is that it allows for gains in efficiency through private sector participation without selling assets to the private sector. Management contracts are also relatively simple and thus easy to develop. Incentives to improve efficiency can be incorporated into these contracts. Moreover, these contracts can be seen as a stepping stone to greater private sector involvement.

On the contrary, it is difficult to separate the operation of the public service and the finance and expansion of the service. Often, these roles are complementary in nature since the expansion of the service may lead to increased profits from operating the expanded service. However, in management contracts, the private party to the partnership is responsible for operating the public service while arrangements will need to be made for financing and expanding the service. Also, if incentives are incorporated, precautions must be taken to prevent inefficient behavior. If a share of the profit is offered to the contractor as an incentive then mechanisms must be in place to ensure that the contractor does not reduce maintenance or engage in other harmful behavior. Similarly, if incentive payments are offered, then the private operator should be prevented from reporting inaccurate and inflated results. Mnagement contract are often used for hotels and port management through private sector. 
Lease Contracts: In a lease contract, the private contractor is responsible for the complete operation and management of the public service. The private operator has the leverage to charge the users and most cases bear the commercial risk which includes the financial risk of managing and maintaining the operation. However, the private partner is not responsible for making any new or replacement investments. Moreover, the quality of service and the tariff to be levied on the consumer is regulated by the government. Under a lease contract, the government owns the asset and is responsible for capital expenditures for new projects, replacement of vehicles, debt service, tariff and cost recovery policies. The government also bears capital investment risk which is generally recovered from the tariff charged by the private operator. In addition to this, the government also receives lease payments.

In lease contracts the profits of the contractor depends on the sale of utilities. Since by lowering the cost of production, the contractor can increase profits, there is an incentive to become efficient. Provision for periodic revisions of the contractor rate using price index formula and establishing good billing and collection practice is unique advantage of lease contracts.

Alternatively, the incentive to increase efficiency may lead to poor maintenance of assets because this can lead to increased profits. This is likely to happen particularly in the end of the contract. Also, in this type of contract the government must set the tariff which is a sensitive issue and may involve complex arrangements (ADB, 2008). Moreover, this type of contract is not appropriate for attracting private finance. Different countries have successfully leased out port terminal, railway line, optic fiber cable to private sector.

Concession Contract: In a concession agreement, the contractor is responsible for the complete delivery of service in a particular region. This contractor is responsible for providing working capital and all capital investments. (However, the public sector may extend finance in the form of Viability Gap Funding) These contracts are usually long term (25-30 years) so that an acceptable return on investment can be made by the private partner. The concessionaire collects tariff from the consumer directly, as per the contract. The government's role is mainly restricted to regulating the price and quality of service. Moreover, in this type of contract, the ownership of all assets remains with the government. One advantage of concessions is that they can be a means of attracting private finance. In addition to this, greater risk can be transferred to the private sector. These contracts also have strong incentives in place to increase efficiency since lower costs will lead to higher profits for the contractor.

The major disadvantage to concessions is that they involve a complex contract which requires the government to have the means to regulate tariffs and performance standards. Because of their long term nature the bidding process and contract design is further complicated. There is also a danger that the contractor may not make new investments if costs cannot be recuperated during the term of the concession. Furthermore, concessions may provide only limited competition because of their complex nature and because of the large investments required which could lead to inefficiencies.

BOT (Build-Operate-Transfer) type contracts are special forms of concession contracts. In BOT contracts, the private partner maintains ownership of the asset throughout the term of the contract. In a BOT project, the private sector finances, builds, and operates a specific new facility and is responsible for operation, maintenance management of the system and also 
bears substantial project risk. In addition to BOT contracts, there are a large number of variations such as BOOT (Build-Own-Operate-Transfer), BOO (Build-Own-Operate), BLT (Built-Lease-Transfer), SOT (Supply-Operate-Transfer), ROT (Rehabilitate-OperateTransfer) etc. Since BOT and similar arrangements are a form of concession, they possess some of the same advantages and disadvantages. The advantages and disadvantages of the particular contract depend upon its specification. In such contracts, preparing the tender and the contract takes time due to its complex nature.

Joint Ventures: Joint ventures are co-owned and managed by the public and private sectors. Both parties must be willing to invest in the new formed company (Special Purpose Vehicle, the SPV) and bear some of the risks in order for the joint venture to function. In a joint venture, government jointly with investor finance, construct, operate and maintain a project for a specified period which may or may not be transferred to government authority at the end of the period. The major advantage of joint ventures is that both the private and public sectors invest in the project. Thus both parties have an incentive to cooperate with each other and operate efficiently. However due to the fact that the government both owns and regulates the joint venture, conflicts of interest can arise. Moreover joint ventures are prone to corruption since they often have less rigorous and formal procurement methods.

In comparing the different models, it can be noted that service contracts, management contracts, and lease/affermage agreements all benefit from substantial competition. This is because these models are relatively simple and thus enable more firms to compete. Moreover, these contracts are relatively short in duration and hence contracts are awarded more often. Consequently, firms compete for contracts more frequently and thus lead to increased competition to the market. Increased competition, both in the market and to the market is important to driving down the cost of providing the public service. Furthermore, concessions, BOT type agreements, and joint ventures differ from the other forms of PPP models in that these agreements require private sector finance. Funds borrowed by the private sector usually entail a higher rate of interest. This makes borrowing more expensive, which can increase the cost of the public service.

These are not the only models of PPPs. There are hybrid models which combine different elements of each of the above models. Because different PPP models differ from each other, they possess different sets of strengths and weaknesses. Some of these models are more appropriate for certain situations and contexts. The exact details of a PPP model depend on the particular project and the context in which it takes place. Factors such as the partners' skills, abilities and the environment in which it will proceed determine the details and form of the partnership.

\section{Factors Relevant to Initiating Public-Private Partnerships (PPP)}

The factors relevant to the best practices vary according to the specifications of the particular project and context in which it exists. However, in order for a partnership to exist, it must be in the interest of all the parties involved. This is complicated by the fact that the interest of the public and the private sector may not be the same. The PPP model aims to take advantage of situations where public and private interest can be aligned to achieve optimal results. This can be achieved by setting a system of incentives and penalties in the contract for both the government and private sector. Moreover, There needs to be a compromise by the different participants to the partnership in order to achieve this. One important area is the rate of return on investment. The private sector will try to maximize profit and will justify it by the risk 
taken in earning that profit. The public sector on the other hand will not be willing to pay more than what it costs to construct the facility. One way to overcome this difficulty is by capping the profit of the private sector. Care must be taken to ensure that this does not encourage the private company to behave inefficiently (Transport Policy and Tourism Section, 2010). Closely related to this issue is the duration of the concession period (in BOT). Attempts must be made at calculating the revenue generated from the project. According to this, the length of the concession should be set so as to satisfy all parties to the contract.

Identification of Needs: To serve the interest of the public sector, the need for the project must first be identified. Identifying the need enables the government to find a suitable solution. This may entail finding the life span of the particular need and whether or not it fluctuates (Zou, Wang, \& Fang, 2008). A public sector comparator (PSC) should also be made to ensure value for money. A PSC is a model that takes into account the cost and risks involved if the project were delivered through the public sector. This is then compared with the PPP model to achieve value for money which is defined as the effective use of public sector resources on capital projects. However, this may be impractical in cases where the lack of public funds is the primary motivator for implementing the PPP model.

Bidding Process: Another area where compromise may be beneficial is in the bidding process. Attempting to ensure competition in the bidding process will go towards achieving optimal results and serving the public interest. By nature, PPPs are complex. The preparation phase of the project involves significant costs. The bidding process can be expensive, and this can be a deterrent to firms from competing. Remuneration by the government for the cost incurred in the bidding process can encourage the private sector to participate. Unfortunately, the increased competition comes at an increased cost to the government (Vining \& Boardman, 2008). Particular care must be taken to avoid inefficient outcomes as a consequence of remuneration. Under normal circumstances, if the cost of preparing the project is not commensurate with revenue earned through operation, then these projects will not be feasible. With remuneration, these projects may become viable since the government bears the cost of preparing bids. Thus remuneration may lead to inefficient results since a public sector project may have been less costly and achieved similar results. On the other hand, if there is enough benefit derived from private sector participation, this same result may be optimal.

Regulation and Accountability: The public sector is more interested in societal objectives which are related to the government's political position and the influence it wields (Zou, Wang, \& Fang, 2008). The government acts not only as a producer but also ensures that the marketplace operates efficiently. This can be achieved through regulation. A sound regulatory framework ensures that partnerships are more efficient and that they optimize resources according to broader policy objectives (Pongsiri, 2002). Another objective of regulation can be to guarantee that societal objectives such as providing important services and ensuring special programs are met (Saltman \& Figueras, 1998; Rosenaue, 1999).

In the contract design phase, the interests of the different parties must be included, and risk properly distributed. But to ensure that the partnership functions properly, the parties to the partnership must be held accountable. Without accountability, the interest of the different partners may be undermined, resulting in failure. Adopting a jurisdictional PPP constitution that contains provisions for transparency will encourage accountability. Some of these provisions may include scheduled budget reporting of all PPPs and the disclosure of all contracts to the public. Certain aspects of the contracts which contain trade secrets can be 
blocked with the aid of a neutral third party (Vining \& Boardman, 2008). In addition to this, the bidding process should be transparent so as to facilitate competition. (Department of Economic Affairs, 2006). PPP projects must also promote policy, procedures and instruments for socio-economic impact assessment and mitigation as part of sustainable development. Allocation of risks vis-à-vis roles and responsibility between government executing agency and private sector sponsor must be equitable. Issues like land acquisition, resettlement and completion of other linked projects (utility relocation etc.) should be part of government's responsibility (Rashed \& Alam, 2010). However, private sponsor should also share the benefit of such PPP projects with that of the affected people. Different development agencies across the world promote its own set of policies and regulations for social and environmental assessment for any PPP project development phase. However, the general guidelines for social and environmental sustainability encompasses the following issues to be ensured by the private sector sponsor the relevant government agency for a PPP project:

- Avoiding land acquisition wherever possible

- If unavoidable, providing compensation as existing market price

- Developing Resettlement plan and monitoring for implementation before the PPP project is being implemented

- Assessing the project's likely positive and negative impacts

- Identifying mitigation measures and any residual negative impacts that cannot be mitigated

- Exploring opportunities for environment enhancement

- Supporting Indigenous people

- Promoting social, community and cultural practices

While the government ensures regulatory mechanism and its implementation for ensuring socio-economic sustainability for a PPP project, the private sector is also accountable for making them happen at implementation level. Few specific concern areas where the private sponsors are accountable have been provided below:

- Use long-term, sustainable and environmentally sound project management plans

- Sustainable consumption and production in the concerned PPP project

- Promote use of environmentally friendly equipment

- Follow international guidelines for human rights resettlement policies and conventions

- Better products and services, which reduce the environmental impacts from the use of energy, and resources

- Cleaner, more efficient production processes, which strengthen competitiveness

- Shifts in consumption towards goods and services with lower impacts

Accountability in the partnership is more certain when the objectives and structure of the partnership is clear and specific. Allocating specific responsibilities to the partners and providing them with incentives and resources to accomplish those responsibilities will further ensure accountability (Stiglitz \& Wallsten, 1999; Rosenaue, 1999). Monitoring progress in attaining the set goals is necessary to holding the partners accountable. If sufficient progress is not made, then the party responsible can be held accountable and necessary changes can be made to achieve the desired results.

Risk Management: Central to the success of PPP projects is the allocation of risk. In general, risk should be allocated to the parties best able to manage them. Usually commercial risk is 
better managed by the private sector while regulatory risk by the public sector. (Department of Economic Affairs, 2006) In practice, allocating risk is difficult because it must first be identified and then allocated. Each party will attempt to minimize their exposure to risk. In the contract, care must be taken to ensure the proper transfer of risk.

The commitment of investment by the private partner allocates risk towards the private partner. This commitment by the private partner is found to be correlated to the performance of the partnership (Pongsiri, 2003). Investing in the partnership motivates the private sponsor to perform because of the risk of losing the amount invested in the partnership. In connection with this, it is generally recommended that partnership with standalone limited liability companies must be approached with caution (Vining \& Boardman, 2008). This is because having standalone limited liabilities reduce the risk borne by the investor. This problem can be further compounded if the limited company has a high debt to equity ratio. Care must be taken in forming partnerships with these companies because they may act inefficiently. One example of this is when difficulties arise in the operation stage. Due to minimal exposure to risk, bankruptcy may be declared by these companies when the resolution of the problem might have been sought. On the other hand, setting up limited liability companies is an attempt at reducing exposure to risk, without which investors may be reluctant to invest.

With respect to infrastructure projects, usage risk is very common. Where government actions can lead to an unacceptable decrease in revenue for the private partner, guarantees must be put in place to prevent such an occurrence. This is crucial to attracting private sector investment. In road infrastructure, for example, a minimum traffic guarantee can be given to the private investor. If a minimum traffic guarantee is given, it must be coordinated with the toll levied on users. If this is not the case, the private partner may set the toll so high that there are few users and the government pays an inflated price for the minimum amount of traffic guaranteed. In this example, the private sector would succeed in transferring all the usage risk to the government.

Moreover, in order for the PPP to be bankable, there must be a balance between risk and reward. The risk undertaken by the private party must be commensurate to the rate of return of investment in the project. Otherwise investment in PPPs will not be justifiable on the part of private investors.

Tariff Rate: A crucial factor with regards to the bankability of the project is the tariff rate. In the case of roads, an optimum ticket or toll price should be set. A toll price that is too high can lead to the unpopularity of the project and subsequent failure while a toll price that is too low may result in a less than expected rate of return. To overcome the possibility of the above scenarios it is important that an optimal model is created and tested at various stages of the project.

\section{Conclusion}

As part promoting sustainable economic development though implementing PPPs in an economy, a common sense approach is crucial. PPPs exist because it benefits all the partners. As such, they must be designed to serve the interest of the partners. In doing so, the benefits of the partnership have to be distributed accordingly, together with the risks. Accountability is necessary to ensure that the partnership functions as it should to promote economic, social and environmental sustainability. 
The specific details of "PPP considerations" with regards to a particular project will depend upon the details of that project and its environment. Moreover, such considerations needs to be assimilated and adapted as lessons are incorporated from new experiences.

\section{References}

ADB. (2008). Public-Private Partnership Handbook. September.

Blaiklock, M. (2003). An introduction to PPP, Public Private Partnerships: A Review of the Key Issues, European Construction Institute, Loughborough University, Loughborough, pp. 7-12.

Cheung, E., Chan, A. P., \& Kajewski, S. (2009). Reasons for implementing public private partnership projects: Perspectives from Hong Kong, Australian and British practitioners. Journal of Property Investment \& Finance, 81-95.

Department of Economic Affairs (DEA) (2006). Facilitating Public-Private Partnership for Accelerated Infrastructure Development in India. New Delhi: Asian Development Bank (ADB) and Ministry of Finance, Government of India.

Department of Transport and Regional Services (2005), Public Private Partnership: Value for Money Sought in Joint Government-private Road Projects, Department of Transport and Regional Services, Australia. Available at < www.dotars.gov.au/transprog/govt_links/ppp.aspx> (Retrieved on 16 January 2006)

Globerman, S., \& Vining, A. (1996). A framework for evaluating the government contracting-out decision with an application to information technology. Public Administration Review, 56, 40-46.

Miraftab, F. (2004). Public Private Partnerships: The Trojan Horse of Neoliberal Development? Journal of Planning Education and Research , 89-101.

Pongsiri, N. (2002). Regulations and public-private partnerships. The International Journal of Public Sector Management , 487-495.

Pongsiri, N. (2003). Public Private Partnerships in Thailand: A Case Study of the Electric Utility Industry. Public Policy and Administration, 69-90.

Rashed, M.A. and Alam, M.M. 2010. Delivering Countywide Cost-Effective and Better Education Services: The Models of Public Private Partnership (PPP), Technics Technologies Education Management, Vol. 5(4), pp. 875- 880.

Regan, M. (2009). A Survey of Alternative Financing Mechanisms for Public Private Partnerships. Research Report, Mirvac School of Sustainable Development, Facultyvof Business, Technology, and Sustainable Development, Bond University. Available at http://www.iaq.com.au/images/PDF/Research/MR\%20Research\%20Report\%20No\% 202.pdf> (Retrieved on 25 January, 2011)

Rosenaue, P. V. (1999). The Strengths and Weaknesses of Public-Private Policy Partnerships. American Behavioral Scientist, 10-34.

Stiglitz, J.E. and Wallsten, S.J. 1999, 'Public-private technology partnership: Promises and pitfalls, American Behavioral Scientist, vol. 43, pp. 52-73.

The Canadian Council for Public-Private Partnerships (CCPPP), (2011). Available at <http://www.pppcouncil.ca/aboutPPP_definition.asp> (Retrieved on January 25, 2011)

Transport Policy and Tourism Section. 2010. A Legal Perspective of Public Private Partnerships. Transport and Tourism Division, United Nations Economic and Social Commission for Asia and the Pacific (UNESCAP).

Vining, A. R., \& Boardman, A. E. (2008). Public Private Partnerships: Eight Rules for Goverments. Public Works Management and Policy, 149-161.

Williamson, O. (1975). Markets and hierarchies: Analysis and antitrust implications. New York: The Free Press.

Zou, P. X., Wang, S., \& Fang, D. (2008). A life-cycle risk management framework for PPP infrastructure projects. Journal of Financial Management of Property and Construction, 123-142. 